\title{
PROJETO OBSERVATÓRIO INTERNACIONAL: UMA ABORDAGEM INTERATIVA DAS RELAÇÕES INTERNACIONAIS PARA OS ESTUDANTES DA TERCEIRA SÉRIE DO ENSINO MÉDIO DAS ESCOLAS DA REGIÃO DE TUBARÃO
}

\author{
Lucas Vicente Comassetto ${ }^{1}$, Milene Pacheco Kindermann ${ }^{2}$
}

\begin{abstract}
RESUMO
O presente relato de experiência destina-se a apresentar o projeto Observatório Internacional, que tem por objetivo levar à comunidade, de maneira acessível e lúdica, as questões internacionais contemporâneas de maior relevância para a sociedade. O projeto está em seu segundo ano de desenvolvimento e tem como foco os estudantes da $3^{\text {a }}$ série do Ensino Médio das escolas da região de Tubarão-SC. Nas atividades do projeto, os estudantes das escolas visitadas têm a possibilidade de fazer indagações, reflexões, suposições e debates sobre as questões abordadas e, assim, construir e reconstruir o seu próprio conhecimento. Os resultados obtidos apontam que o projeto foi bem dimensionado, alcança os objetivos definidos e está se tornando um interessante mecanismo de ensino-aprendizagem.

Palavras-chave: Relações Internacionais; Atualidades; Quiz; Cidadania; Extensão.
\end{abstract}

\begin{abstract}
The following experience report is intended to present the project "Observatório Internacional", which aims to deliver to society, through an accessible and ludic way, the most relevant contemporary international issues. The project is in its second year and it is intended for students in the third year of high schools located in the city of Tubarão (SC). During the activities of the project, students have the opportunity to ask questions, reflect, discuss suppositions and debate about the matters addressed and, consequently, build and rebuild their own knowledge. The results obtained show that the project was greatly dimensioned, reached its defined goals and has become a interesting mechanism for learning and teaching.
\end{abstract}

Keywords: International Relations; Current Affairs; Quiz; Citizenship; Extension.

\footnotetext{
${ }^{1}$ Graduando em Relações Internacionais - UNISUL / Tubarão-SC. E-mail: vicenlucas@ gmail.com.

${ }^{2}$ Doctora en Derecho y Ciencias Sociales - UMSA / Buenos Aires.
} 


\section{INTRODUÇÃO}

A educação básica brasileira passa por um momento de dificuldade. Os baixos índices de aprendizagem, as precárias estruturas físicas das escolas, a má formação dos professores, as condições inadequadas de trabalho, a desvalorização dos profissionais de educação e a falta de políticas públicas eficazes para a correção desses e de outros problemas refletem-se na inviabilidade de se propagar um ensino-aprendizagem de excelência no Brasil. Logo, desenvolver uma pedagogia que, para além de problematizar conteúdos, possibilite que a educação seja utilizada pelos educandos e educadores como um instrumento político de emancipação social torna-se uma tarefa a ser perseguida (SILVA; SOUZA, 2013; ESTADO DE SANTA CATARINA, 2016; BRASIL, 2016).

O Curso de Relações Internacionais da Universidade do Sul de Santa Catarina (UNISUL) tem por objetivo geral "formar cidadãos capazes de se inserir num mundo globalizado, em constante transformação e de contribuir para o desenvolvimento sustentável deste, com postura crítica, inovadora, empreendedora e ética" (UNIVERSIDADE DO SUL DE SANTA CATARINA, 2013). Nos objetivos específicos do Curso, consta que o egresso deve apresentar conhecimentos amplos e atualizados sobre as Relações Internacionais (RI) na atualidade e que deve fazer a aproximação com a comunidade por meio da extensão universitária.

No anseio de contribuir com um ensino-aprendizagem de excelência no Brasil, com o atingimento das metas do Curso de Relações Internacionais da UNISUL e com a materialização do princípio constitucional de indissociabilidade entre ensino, pesquisa e extensão foi concebido o projeto Observatório Internacional.

O projeto justificou-se pela necessidade de acompanhar as situações da atualidade, que diziam respeito ao desempenho das organizações internacionais de caráter governamental e não-governamental, ao mapeamento dos conflitos internacionais e das suas soluções, à proteção internacional de Direitos Humanos, ao desenvolvimento do comércio e das relações econômicas e sociais internacionais, entre outras ocorrências que chamavam a atenção na mídia. O monitoramento das situações permitiu que fossem organizados dados para que estudantes, professores e público em geral pudessem utilizá-los em seus estudos, na abordagem dos conteúdos ministrados nas disciplinas, nas atividades acadêmicas e no mundo do trabalho. No entanto, apenas observar e registrar apresentavam-se insuficientes. Nesse sentido, o Observatório prestou-se a divulgar as notícias e dados veiculados na mídia, 
apresentando-os de maneira acessível para públicos diversos. Em especial, o público das escolas da região de Tubarão.

De acordo com o Plano de Desenvolvimento Regional da Agência de Desenvolvimento Regional de Tubarão (antiga Secretaria de Desenvolvimento Regional), estudos diagnósticos da região apontavam para a necessidade de promover a universalização e a melhoria da qualidade do Ensino Médio e o aumento gradativo do tempo médio de estudo da população. Além disso, também se destacava a importância de projetos de educação continuada para professores, a atenção às atividades culturais e históricas das comunidades e a ampliação da infraestrutura escolar para atividades culturais e esportivas. O mesmo plano previa como fraquezas da área educacional: "docentes desmotivados", "escola não atrativa" e "falta de comprometimento das universidades/faculdades". Tais pontos foram trabalhados pelo presente projeto de extensão, que buscou dar contribuições significativas para a reversão desse quadro (ESTADO DE SANTA CATARINA, 2012).

O objetivo geral do projeto foi levantar dados sobre as questões internacionais contemporâneas de grande relevância para a sociedade, de modo a apresentá-las à comunidade externa, principalmente aos estudantes da $3^{\text {a }}$ série do Ensino Médio, de maneira acessível e lúdica, instigando a curiosidade deles sobre o contexto internacional atual.

Para a consecução desse objetivo estabeleceu-se que, semanalmente, fossem levantadas, em meios jornalísticos digitais, notícias que impactassem as RI; que se registrassem tais notícias, de maneira organizada, no blog do observatório; que, periodicamente, fossem produzidas listas de perguntas e respostas a respeito das notícias levantadas e publicadas no blog, com intuito de compor o quiz a ser levado às instituições escolares para chamar a atenção dos estudantes acerca dos principais acontecimentos mundiais; e que, sistematicamente, o processo de apropriação das notícias publicadas no blog fosse avaliado.

\section{PROCEDIMENTOS METODOLÓGICOS}

Acredita-se que, na medida em que se conhecem as mais importantes ocorrências ao redor do mundo, passa-se a tomar consciência de que não estamos sozinhos, que outros indivíduos compõem conosco a humanidade e que, se problemas são comuns, as soluções também podem ser. Isso contribui para que princípios como o da solidariedade dos Direitos Humanos, como a busca de soluções pacíficas, como o desenvolvimento econômico e social 
dos povos - princípios consagrados na Carta das Nações Unidas ${ }^{3}$-, sejam divulgados, e que a tomada de consciência sobre o mundo em que vivemos amplie os horizontes de nosso pensamento. Por essas e muitas outras vantagens, justificou-se levar para as escolas uma estrutura que chamasse a atenção, de maneira lúdica, para as questões internacionais, tornando o estudo dos temas e a própria escola mais atrativos.

O projeto teve como público alvo tanto a comunidade interna da UNISUL e do Curso de Relações Internacionais quanto os estudantes das escolas da região de Tubarão e demais pessoas da comunidade.

Para o desenvolvimento das atividades, o projeto foi submetido ao edital de bolsas de estudo, pesquisa e extensão oferecidas pelo Fundo de Apoio à Manutenção e ao Desenvolvimento da Educação Superior do Governo do Estado de Santa Catarina (FUMDES - edital do artigo 171). Em razão de ter sido aprovado, foram dedicadas 12 horas semanais de trabalho, por parte do estudante bolsista, e 1 hora semanal, por parte do professor orientador.

A metodologia de ação se deu por meio de: a) levantamento, nos meios de comunicação, das notícias que tratavam de temas importantes da agenda das RI, publicandoas no blog do Observatório; b) a produção, a partir das notícias postas no blog, das perguntas e respostas que compuseram o quiz; c) a produção do cenário do jogo, composto de um planisfério gigante (no tamanho 2,00 metros X 3,00 metros), que foi utilizado como tapete e como painel, tendo sido levado para as escolas e eventos; d) a aplicação do jogo, individualmente ou por equipes, nas escolas e eventos, com a parceria de professores e gestores escolares, desenvolvendo a motivação dos participantes para os temas da agenda internacional atual; e) a divulgação do blog/site do Observatório para a comunidade.

As atividades do projeto foram iniciadas em 2015, tendo sido programadas para serem desenvolvidas por um período de dois anos. Semanalmente, o blog era alimentado, com a inserção de notícias. Mensalmente, pelo menos uma escola era visitada. Os estudantes

\footnotetext{
${ }^{3}$ A Carta das Nações Unidas é o documento constitutivo da Organização das Nações Unidas (ONU). Assinada em São Francisco, aos 26 de junho de 1945, após o encerramento da Conferência das Nações Unidas sobre Organização Internacional, entrou em vigor aos 24 de outubro daquele mesmo ano. Neste documento foram consagradas, dentre outras coisas, os princípios e propósitos da organização. Em seu preambulo ressalta "NÓS, OS POVOS DAS NAÇÕES UNIDAS, RESOLVIDOS a preservar as gerações vindouras do flagelo da guerra, que por duas vezes, no espaço da nossa vida, trouxe sofrimentos indizíveis à humanidade, e a reafirmar a fé nos direitos fundamentais do homem, na dignidade e no valor do ser humano, na igualdade de direito dos homens e das mulheres, assim como das nações grandes e pequenas, e a estabelecer condições sob as quais a justiça e o respeito às obrigações decorrentes de tratados e de outras fontes do direito internacional possam ser mantidos, e a promover o progresso social e melhores condições de vida dentro de uma liberdade ampla.

E PARA TAIS FINS, praticar a tolerância e viver em paz, uns com os outros, como bons vizinhos, e unir as nossas forças para manter a paz e a segurança internacionais, e a garantir, pela aceitação de princípios e a instituição dos métodos, que a força armada não será usada a não ser no interesse comum, a empregar um mecanismo internacional para promover o progresso econômico e social de todos os povos. [...]" Estes valores e propósitos estão firmados também nos artigos $1^{\circ}$ e $2^{\circ}$ da Carta da Nações Unidas (BRASIL, 1945).
} 
atendidos eram, majoritariamente, concluintes do Ensino Médio, haja vista que as atividades do Observatório Internacional se propõem, principalmente, a despertar os estudantes concluintes do Ensino Médio para o acompanhamento de jornais e revistas eletrônicas sobre as notícias de repercussão internacional, de maneira a contribuir também com a preparação deles para o Exame Nacional do Ensino Médio (ENEM) e para os vestibulares.

\section{DESENVOLVIMENTO}

\subsection{Relato}

Em março de 2015, seguindo cronograma definido no edital 688/2014 do Artigo 171, o projeto Observatório Internacional passou a ser implementado. $\mathrm{O}$ blog do projeto foi criado - endereço eletrônico: http://observatorioiinternacional.blogspot.com - para a publicação de notícias da área de RI. As notícias publicadas no blog foram transformadas em perguntas e tais perguntas compuseram o quiz aplicado em escolas e eventos.

Figura 1. Imagem do blog do projeto.

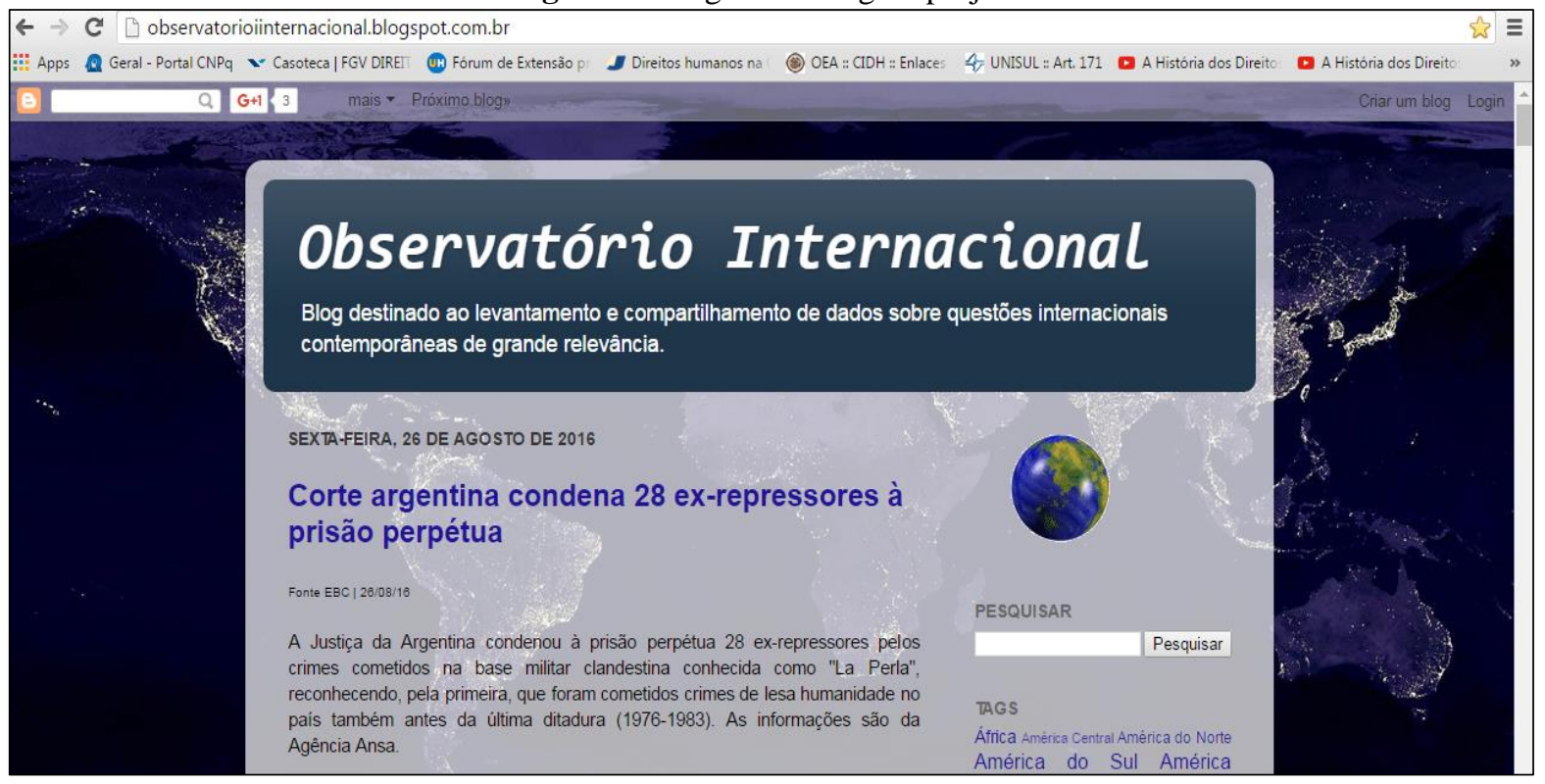

Fonte: Acervo dos autores, 2016.

Foi preparado o tapete que serviu de base para a aplicação do quiz nas escolas, custeado com o patrocínio da universidade, e também os cartões utilizados para a realização do jogo. Para a finalização da aplicação das atividades nas turmas, foi feito um pequeno flyer para convidar os estudantes a visitar o blog, tendo contato com as notícias internacionais ali organizadas. E, por último, foi composto um formulário de avaliação da atividade, a ser preenchido individualmente. 
Figura 2. Tapete de aplicação do jogo.

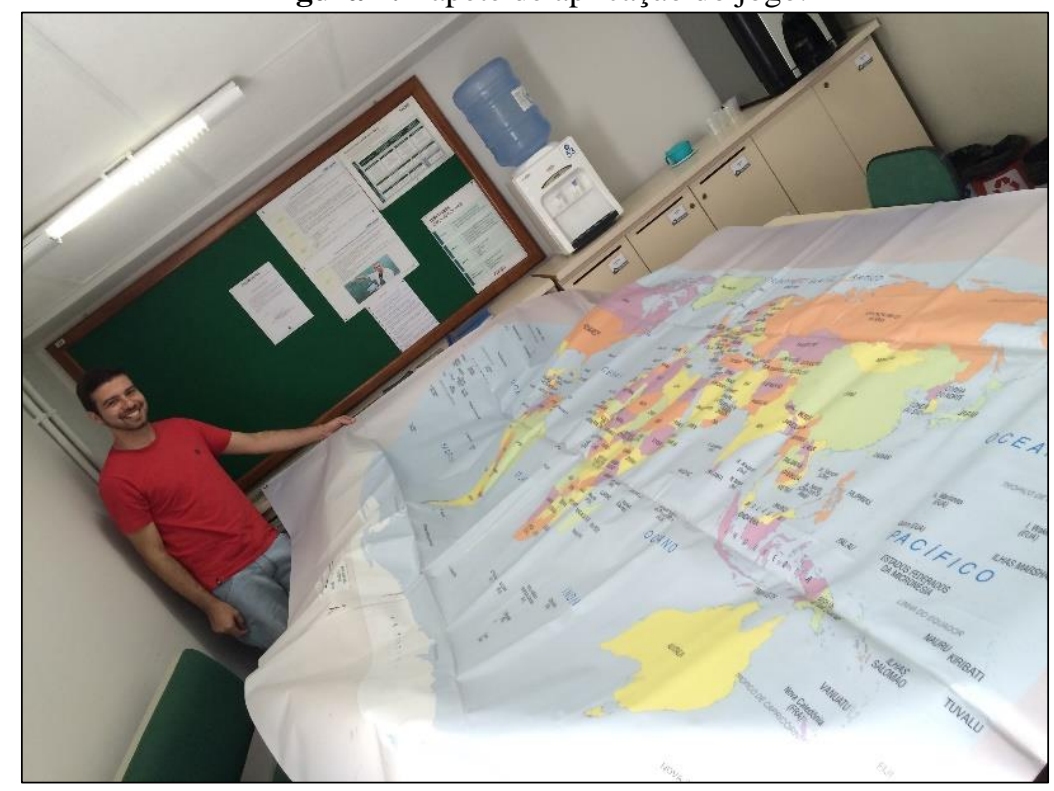

Fonte: Acervo dos autores, 2016.

Figura 3. Perguntas que compõem o quiz.

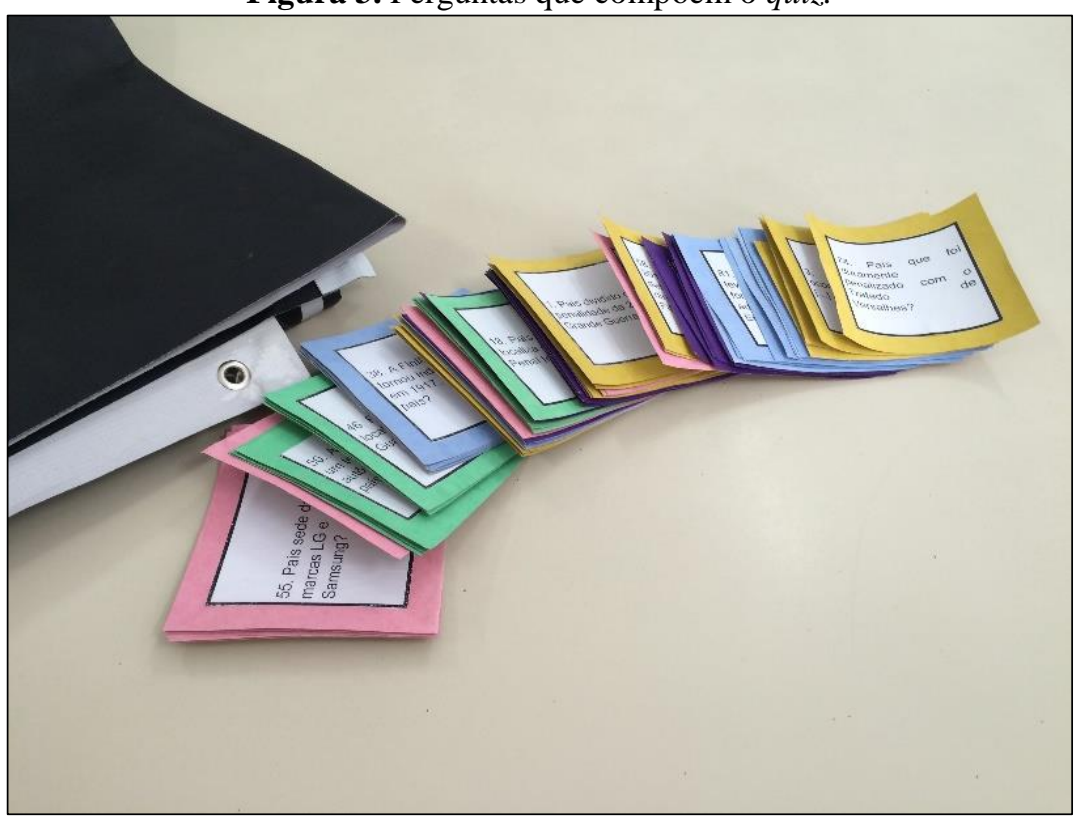

Fonte: Acervo dos autores, 2016.

As escolas selecionadas para receberem as atividades do projeto são instituições atendidas pelos graduandos da UNISUL por meio do Programa Institucional de Bolsa de Iniciação à Docência do Governo Federal (PIBID ${ }^{4}$ ) e/ou são escolas de Ensino Médio, dos

\footnotetext{
${ }^{4}$ O Programa Institucional de Bolsa de Iniciação à Docência (PIBID) é um programa de incentivo e valorização do magistério e de aprimoramento do processo de formação de docentes para a educação básica, vinculado à Coordenação de Aperfeiçoamento de Pessoal de Nível Superior (CAPES). Ele oferece bolsas para que alunos de licenciatura exerçam atividades pedagógicas em escolas públicas de educação básica, contribuindo para a integração entre teoria e prática, para a aproximação entre universidades e escolas e para a melhoria de qualidade da educação brasileira (UNIVERSIDADE FEDERAL DOS VALES DO JEQUITINHONHA E MUCURI, 2016).
} 
setores público e privado de ensino, listadas no sítio eletrônico oficial da Secretaria de Estado da Educação de Santa Catarina (SED/SC) - listadas no endereço eletrônico dessa Secretaria: http://serieweb.sed.sc.gov.br/cadueportal.aspx.

Figura 4. Aplicação do jogo no Centro de Educação Profissional Diomício Freitas, Tubarão.

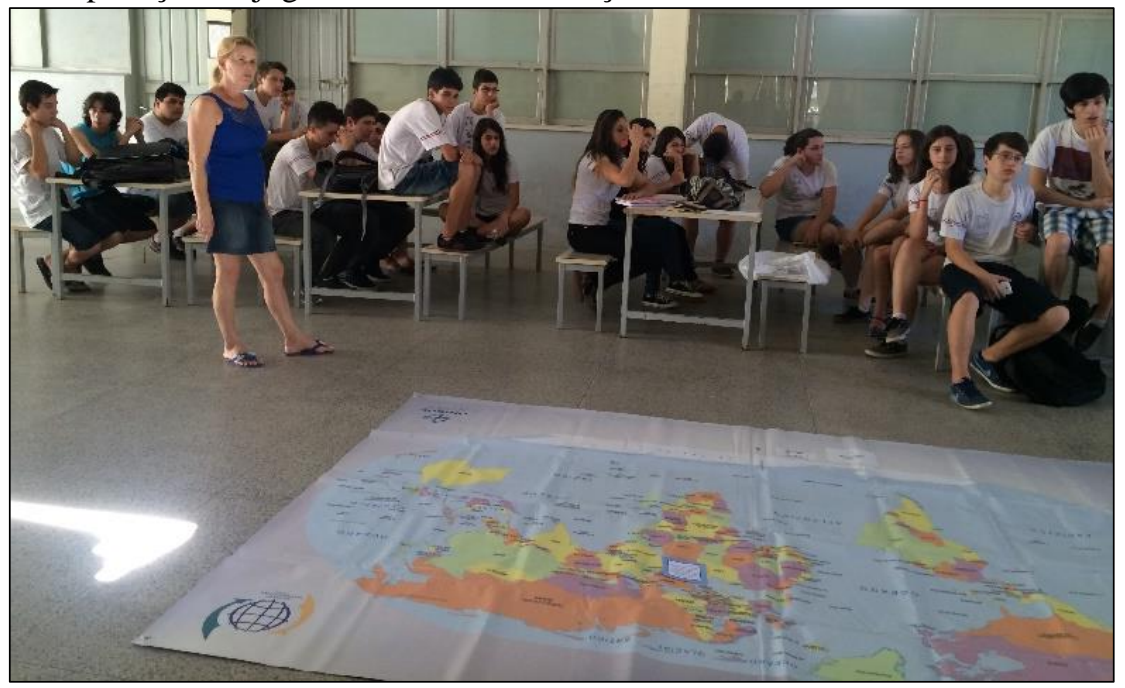

Fonte: Acervo dos autores, 2016.

Figura 5. Aplicação do jogo na Escola de Educação Básica Henrique Fontes, Tubarão.

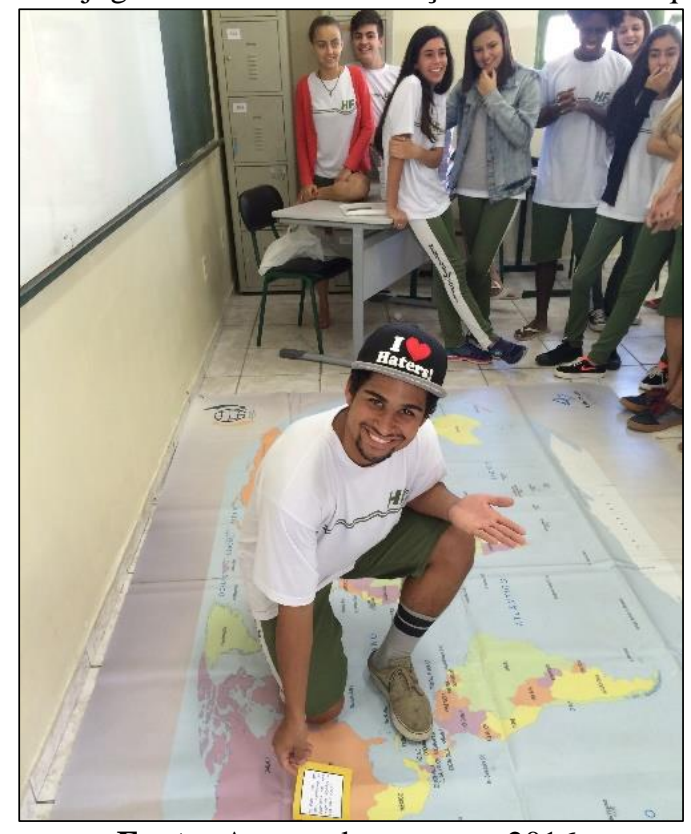

Fonte: Acervo dos autores, 2016.

Até o momento, 9 unidades de ensino e um evento universitário foram contemplados com os trabalhos do projeto, 27 turmas foram visitadas e um total de 796 estudantes foram diretamente atingidos. Em grande parte dessas instituições, as atividades foram realizadas em parceria com professores de atualidades, história e/ou geografia e com o apoio das equipes pedagógica e diretiva. 
Figura 6. Aplicação do jogo no Serviço Nacional de Aprendizagem Industrial, Tubarão.

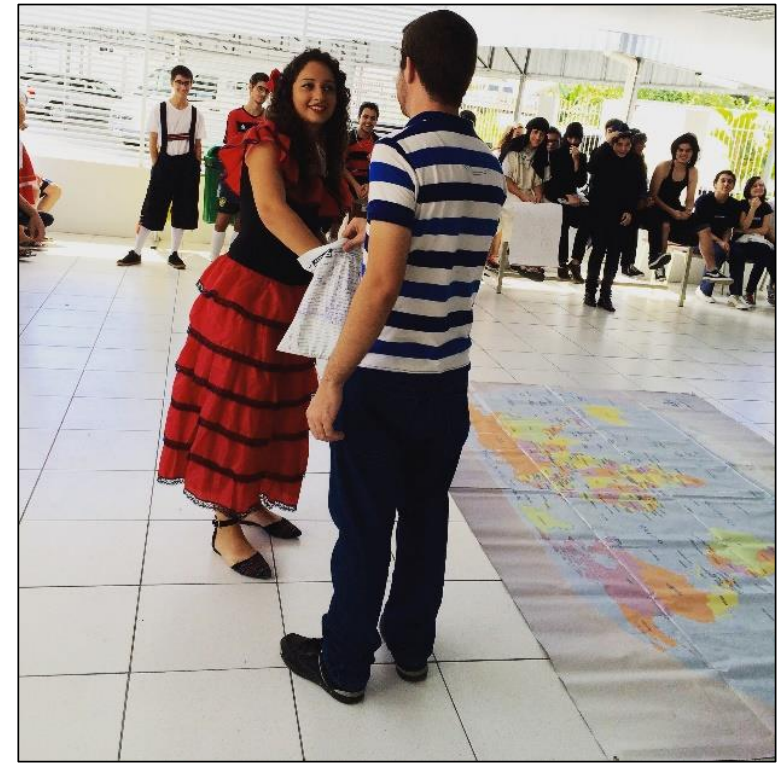

Fonte: Acervo dos autores, 2016.

Figura 7. Aplicação do jogo na Escola Técnica do Comércio de Tubarão.

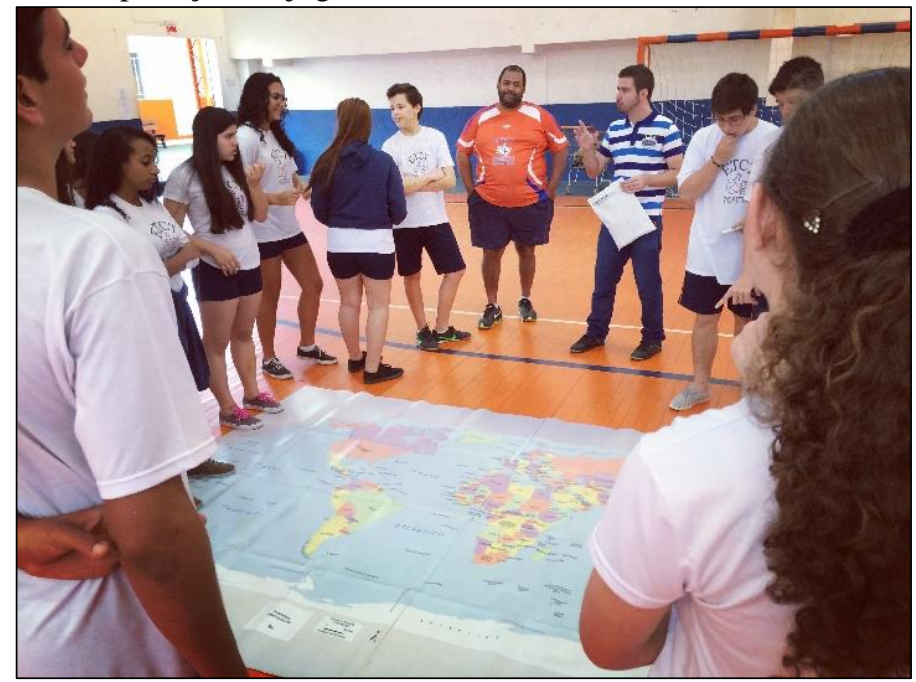

Fonte: Acervo dos autores, 2016.

O número de estudantes contemplados e a quantidade de turmas visitadas, até o momento, chamam a atenção. Contudo, mais significativo tem sido o nível das participações e o despertar que elas têm gerado em cada estudante.

Os jogos têm se realizado de forma individual ou em grupo, com os estudantes disputando entre si o quiz. 
Figura 8. Disputa, em grupo, do jogo no Instituto Estadual de Educação Ernesto Alves, Rio Pardo (RS).

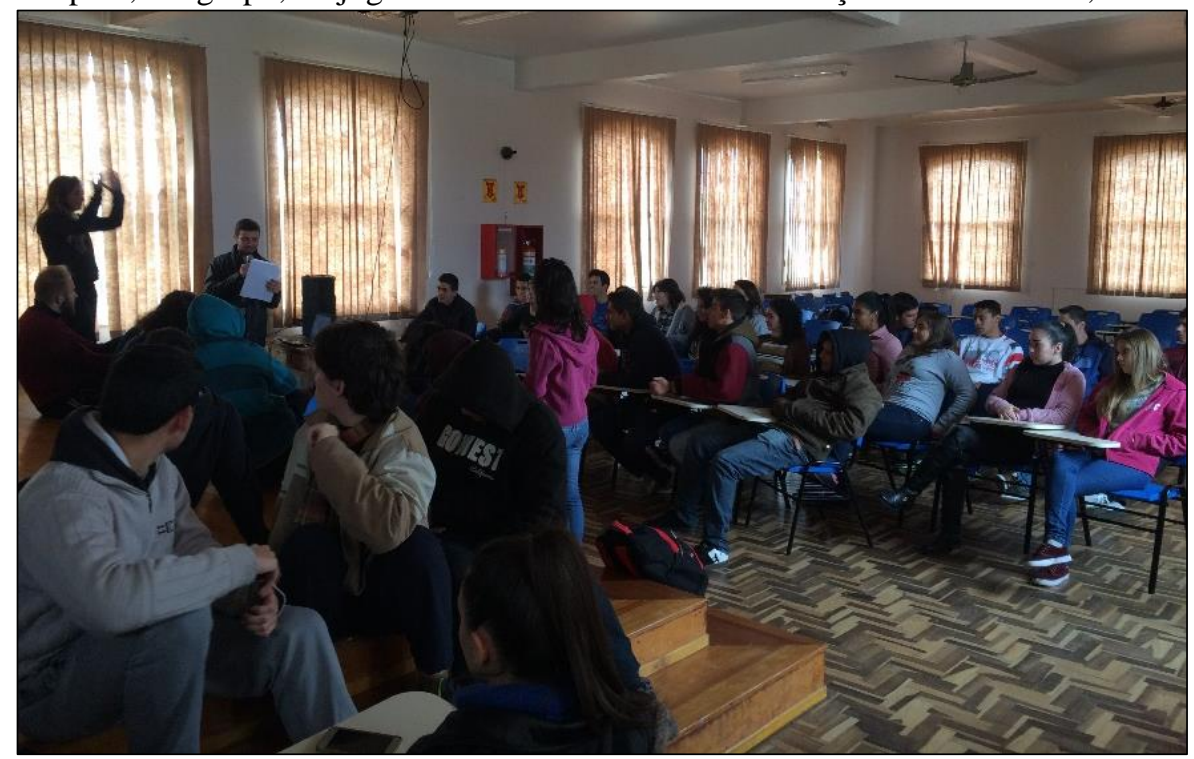

Fonte: Acervo dos autores, 2016.

Figura 9. Realização do quiz, de forma individual, na Escola de Educação Básica Dr. Renato Ramos da Silva.

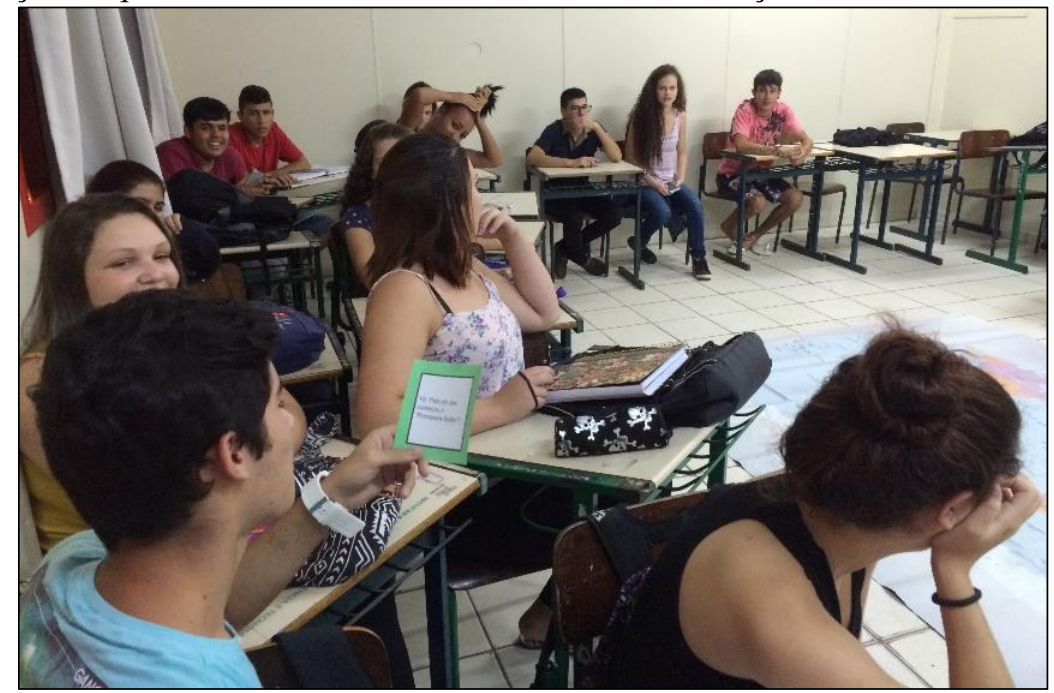

Fonte: Acervo dos autores, 2016.

Todavia, tem se destacado que o objetivo da atividade não é premiar o estudante mais bem informado sobre os assuntos da seara internacional, tampouco meramente transferir conhecimentos. As perguntas são trabalhadas de modo a permitir a abertura de oportunidades para indagações, sugestões, raciocínios, opiniões e demais interações positivas que possibilitam ao estudante compreender, à sua própria maneira, o assunto dissertado, produzir e construir o seu próprio conhecimento e fazer da educação um mecanismo de empoderamento social e político. 
Ainda, o jogo foi demonstrado em evento da universidade, de exposição dos seus cursos e programas (Vitrine das Profissões), em setembro de 2015. Neste evento não houve a coleta de avaliações, pois se tratava de demonstração da atividade.

Figura 10. Demonstração do game na Vitrine das Profissões Campus Tubarão.

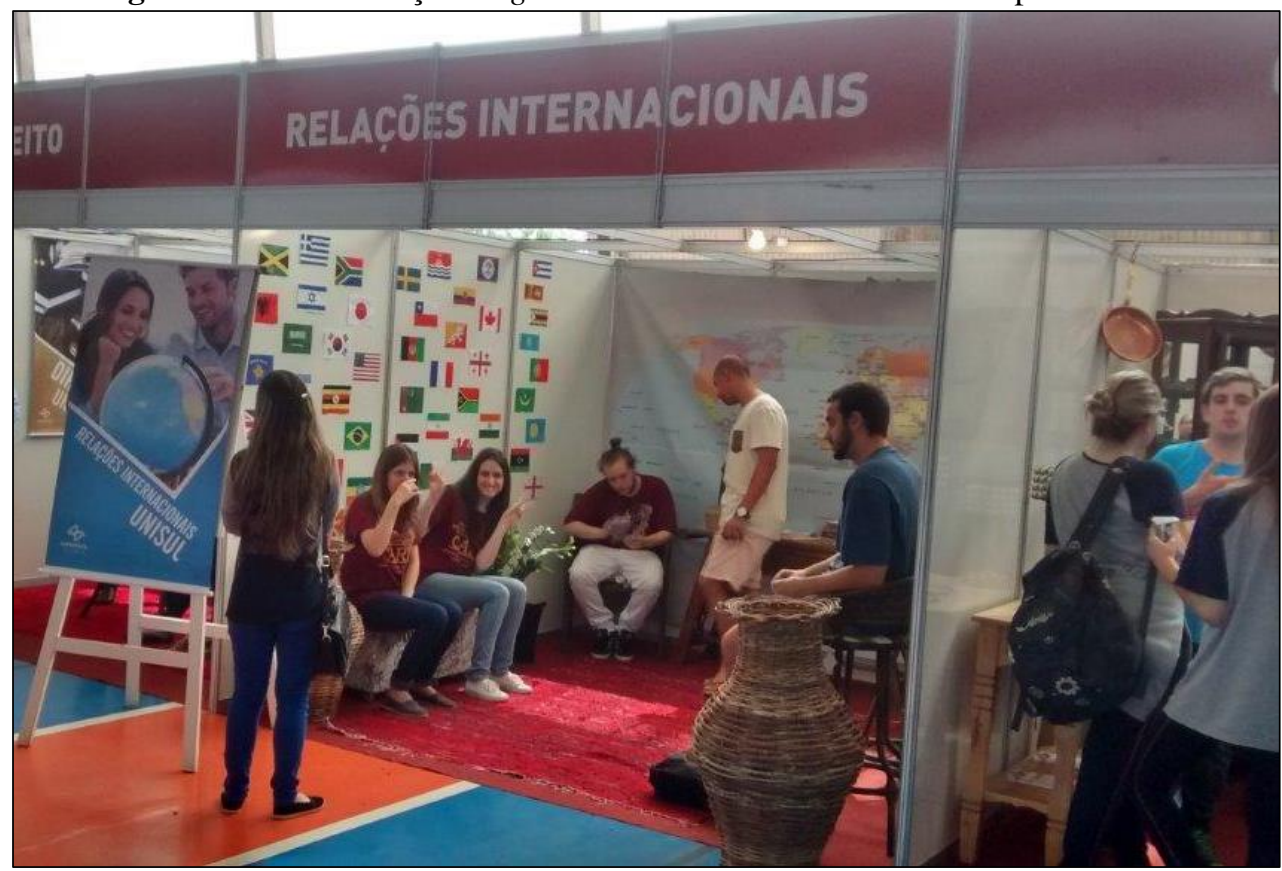

Fonte: Acervo dos autores, 2015.

\subsection{Resultados}

Até o momento, das 9 escolas contempladas com as atividades do projeto, aproximadamente 55\% eram instituições da rede pública de ensino, e do total de 796 estudantes atingidos, 409 eram da rede pública, conforme apresentado na tabela 1 .

Tabela 1. Relação de instituições, número de estudantes e turmas atendidas pelo projeto entre os anos 2015 e 2016.

\begin{tabular}{|c|c|c|c|c|}
\hline INSTITUIÇÃO DE ENSINO & SETOR & № ESTUDANTES & $\begin{array}{c}\text { QTD. } \\
\text { TURMAS }\end{array}$ & TURMAS \\
\hline DEHON - TUBARÃO & PRIVADO & 175 & 4 & 20 e 30 \\
\hline CEDUP - TUBARÃO & PÚBLICO & 37 & 2 & 3은 \\
\hline HENRIQUE FONTES - TUBARÃO & PÚBLICO & 272 & 9 & 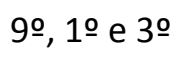 \\
\hline SENAI - TUBARÃO & PRIVADO & 60 & 2 & 3은 \\
\hline RENATO RAMOS - LAGUNA & PÚBLICO & 40 & 2 & 3은 \\
\hline ESCOLA JOVEM - TUBARÃO & PÚBLICO & 40 & 2 & 3은 \\
\hline EEMAL - LAGUNA & PÚBLICO & 20 & 1 & 3은 \\
\hline ETC - TUBARÃO & PRIVADO & 84 & 3 & 10,2 e e $3 \circ$ \\
\hline FUNDAÇÃO BRADESCO - LAGUNA & PRIVADO & 68 & 2 & 3음 \\
\hline TOTAL & & 796 & 27 & \\
\hline
\end{tabular}

Fonte: Elaborado pelos autores, 2016. 
Esses dados são bastante significativos, pois o projeto conseguiu atingir o público de estudantes de ambos os setores da educação de Ensino Médio (redes pública e privada de ensino).

Destaca-se que o jogo foi aplicado também numa escola no Estado do Rio Grande do Sul, no município de Rio Pardo, em razão de deslocamento pessoal do bolsista. Para efeitos de contabilização dos dados avaliativos, no entanto, os indicadores coletados nessa escola serão descartados, por tratar-se de projeto destinado ao público-alvo das escolas da região de Tubarão.

Merece consideração que o número de escolas procuradas pelo projeto foi além das 9 participantes, sendo que 8 escolas do grupo inicial de foco não se disponibilizaram para a realização da atividade, por diferentes razões, como pouco interesse da direção da escola na atividade, dificuldade de identificação de professor local para acompanhar os trabalhos, comprometimento do calendário escolar em razão de períodos de greve ou não abertura na agenda para conhecimento do projeto.

Outros inconvenientes foram percebidos nas visitas às escolas, a citar a falta de organização prévia para a realização do jogo, a ausência da pessoa que se comprometeu em recepcionar o bolsista, a falta de divulgação prévia da atividade aos estudantes. Não obstante, essa realidade não se fez presente em grande parte das escolas em que o projeto foi recepcionado como algo importante pelos gestores das instituições e realizado sem contratempos.

Merece menção o fato de os professores de algumas escolas terem sido os maiores apoiadores do quiz. Em determinadas instituições, eles contribuíram com o planejamento e desenvolvimento da atividade, possibilitaram espécies de gincanas entre as turmas, financiaram a compra de balas e pirulitos distribuídos aos estudantes, deram suporte e trabalharam com o aluno extensionista os assuntos abordados nas perguntas do jogo, bem como situaram os estudantes sobre a importância da atividade para o desenvolvimento de um espaço de construção e reconstrução do saber e da consciência crítica.

Dados importantes quanto à aplicação do jogo nas turmas podem ser percebidos nas avaliações feitas pelos estudantes acerca das atividades do projeto, conforme ilustrado no gráfico 1. Nessas avaliações, os participantes atribuíram notas de zero a dez tanto para a sua própria performance (os quesitos eram "compreensão das regras do jogo" e "familiaridade com as perguntas"), quanto para a qualidade da atividade (com os quesitos "atratividade do jogo" e "contribuição do jogo para o seu aprendizado"). Em nenhum momento essa avaliação teve caráter obrigatório ou incidiu sobre as atividades escolares dos estudantes (seja em notas 
ou participações). No entanto, os questionários eram preenchidos de boa vontade pelos participantes. Foram preenchidos ao longo das visitas 175 questionários, o que em termos percentuais sobre o total de participantes refere-se a cerca de $22 \%$.

Gráfico 1. Avaliação das atividades do projeto por instituição de ensino (IE) visitada.

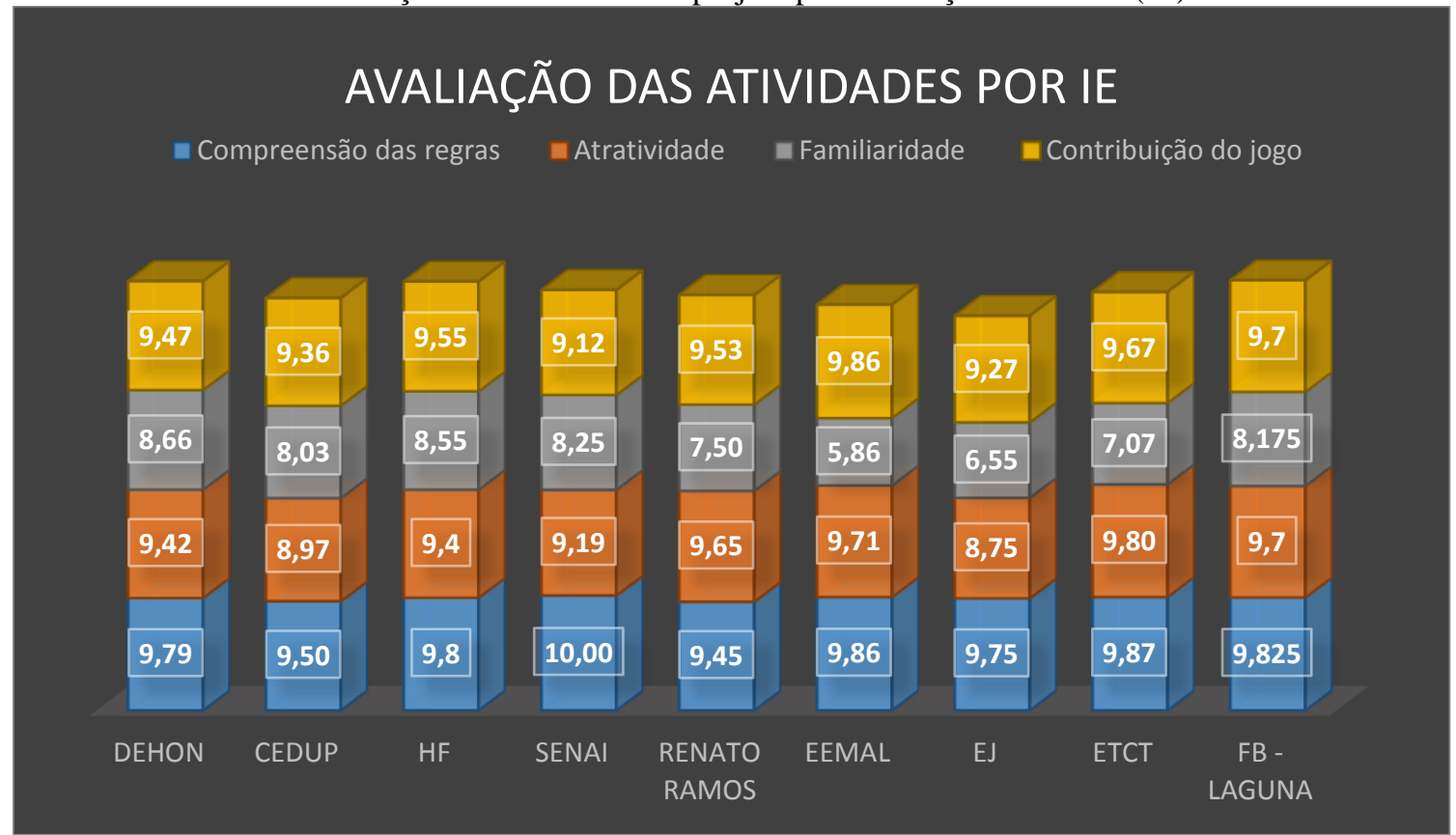

Fonte: Elaborado pelos autores, 2016.

O gráfico 1 permite perceber que, quanto ao entendimento das regras do jogo aplicado, os estudantes apresentaram, em sua autoavaliação, um excelente desempenho, ficando com a média geral de 9,76 pontos, o que revela que o instrumento aplicado estava adequado aos objetivos a que se destinava.

No mesmo gráfico, percebe-se que, quanto à atratividade da atividade proposta, a avaliação média ficou em 9,40 pontos, o que indica que o game foi interessante para a abordagem dos conteúdos ali apresentados.

No que se refere à familiaridade com o tema, pode-se perceber que as notas atribuídas em cada escola apresentam disparidades entre si. A melhor avaliada pontuou-se com 8,66, enquanto que houve escola que se atribuiu a média de 5,86 pontos. Acima de 9 pontos nenhuma escola recebeu avaliação, sendo 5 escolas na faixa de 8 pontos, duas escolas com 7 pontos e 2 escolas abaixo de 7 pontos. A média deste quesito ficou em 7,62.

No quesito contribuição do jogo para a aprendizagem, as médias ficaram todas acima dos 9 pontos, totalizando a média global de 9,50, o que pode ser considerado uma excelente avaliação da atividade para o alcance dos propósitos a que se destinava. 
Ainda, outra atividade do projeto foi a construção e manutenção do blog de notícias. Do dia em que foi ao ar até a data atual (04/09/16), as páginas do blog já contaram com um total de 1.468 visualizações.

Para o estudante bolsista, o desenvolvimento das atividades do projeto Observatório Internacional constituíram-se como um instrumento para o cumprimento de sua missão pessoal e social.

A implementação do game nas escolas obteve dois resultados concretos para o extensionista. Primeiro, permitiu que ele se deparasse com o contraste entre as redes de ensino privada e pública. Nas escolas da rede privada foi perceptível estarem à disposição os recursos físicos, humanos e financeiros necessários para o desenvolvimento das atividades escolares. Já nas escolas da rede pública, essa percepção divergiu. Notou-se, por meio das visitações, a inadequada estrutura física das escolas (prédios antigos que provavelmente há muito tempo não são reformados e se encontram com rachaduras, infiltrações, mofos e com pouca iluminação e ventilação), a carência de profissionais qualificados (os estudantes de duas escolas informaram ao extensionista que seus professores jamais haviam trabalhado os assuntos tratados no game), a carência de organização escolar quanto às atividades (em várias escolas foi agendada a visitação, mas as equipes diretivas se esqueceram de comunicar aos professores e estudantes) e à disciplina dos alunos (durante a realização do jogo em uma escola, os alunos foram liberados pela direção para fazerem o que bem entendessem, o que acarretou em abandono da atividade). Segundo, permitiu que a constatação desse cenário discrepante se constituísse como motivação para o desenvolvimento dos trabalhos, tendo em conta que, no olhar do bolsista, o projeto tem se materializado como uma forma de transformação social.

\section{DISCUSSÃO}

Com a verificação dos resultados alcançados, percebeu-se que a realização das atividades inicialmente previstas no projeto não sofreu comprometimento, com exceção das dificuldades de acesso a algumas escolas preliminarmente mapeadas e certa desorganização em alguns colégios na recepção da atividade.

O impacto da aplicação do jogo nas escolas mostrou-se positivo, permitindo que se observasse que a maioria dos estudantes, ao final do jogo, identificou que a atividade contribuiu com a transformação e/ou construção do conhecimento.

Os itens avaliativos da qualidade do jogo sugerem que a atividade foi bem dimensionada para que as questões internacionais contemporâneas de relevância pudessem ser 
apresentadas de maneira acessível e lúdica, instigando a curiosidade dos estudantes das escolas visitadas para as temáticas apresentadas.

No quesito de familiaridade com os assuntos tratados no game, apesar de avaliarem mediana familiaridade, se agrupadas as escolas por suas redes de ensino, percebe-se que nas escolas privadas a média manifestada pelos estudantes foi de 8,03 pontos, enquanto que nas escolas públicas (nas quais se inserem as duas escolas que atingiram médias abaixo de 7 pontos) a média foi de 7,29 pontos. Nesse diapasão, pode-se perceber que os estudantes das escolas particulares apresentaram média acima dos estudantes das escolas públicas, o que requer maior atenção dos professores e dirigentes desses estabelecimentos quanto à qualidade dos serviços prestados.

Causou espanto ao extensionista perceber, com base no relato dos estudantes, que em quatro escolas assuntos históricos, sociais e políticos importantes foram apresentados a eles pela primeira vez no exercício do jogo. Essa percepção fez com que o bolsista questionasse o que os professores e as escolas vêm fazendo para cumprir com os seus papéis constitucionais, sociais e humanos. Também tornou aguda sua vontade de contribuir com a conversão dessa conjuntura por meio de ações sociais como as que têm sido executadas no âmbito do projeto de extensão Observatório Internacional.

Dado o exposto, acredita-se que o projeto contribui com a missão cidadã da escola, dando possibilidade para que os estudantes se percebam como cidadãos internacionais - não apenas seres territorialmente isolados - e agentes transformadores da realidade e da sociedade local, regional e global.

\section{CONSIDERAÇÕES FINAIS}

O projeto alcançou os objetivos estipulados e encontra-se próximo dos resultados esperados. As questões internacionais contemporâneas de grande relevância para a sociedade foram levantadas e apresentadas à comunidade, principalmente aos estudantes da $3^{\text {a }}$ série do Ensino Médio dos colégios de Tubarão e região, de maneira acessível e lúdica, criando ambientes propícios para a formação de indagações, reflexões, debates e construção e/ou reconstrução do conhecimento. Semanalmente, foram levantadas, em meios jornalísticos digitais, notícias que impactaram as RI. Foram publicadas, de maneira organizada, tais notícias no blog do observatório. Periodicamente, foram produzidas perguntas e respostas a partir das notícias publicadas no blog, compondo o quiz levado às instituições escolares. Sistematicamente, o processo de apropriação das notícias publicadas no blog foi examinado por meio da avaliação das atividades por parte dos estudantes. Essas ações ainda continuam. 
Espera-se contemplar com as atividades do projeto Observatório Internacional cerca de 20 escolas da região selecionada e atingir aproximadamente 2.000 estudantes. Até o momento, 9 educandários foram visitados e 796 estudantes foram atingidos. Estima-se que até o término das atividades (dezembro de 2016) ter-se-á chegado aos resultados esperados ou ido além deles.

Interessante destacar a parceria realizada com a Comunidade de Internacionalistas (organização sem fins lucrativos, integrada por acadêmicos da área de Relações Internacionais) para continuidade das atividades do projeto e ampliação da área geográfica de atuação.

Com essa parceria, espera-se que a partir de 2017, sob o nome de RI Nas Escolas, as atividades realizadas pelo projeto Observatório Internacional sejam adaptadas e implementadas em outras regiões e Unidades da Federação, ampliando o contingente de estudantes diretamente atingidos.

\section{AGRADECIMENTOS E FONTES DE FINANCIAMENTO}

O projeto Observatório Internacional foi financiado por meio de bolsa de extensão do FUMDES, fomentado pelo Governo do Estado de Santa Catarina por intermédio da SED com recursos provenientes do Artigo 171 da Constituição Estadual.

Para o desenvolvimento de seus trabalhos, o projeto contou com apoio de algumas pessoas, instituições e departamentos. Faz-se importante agradecer a Unisul, em especial a Sra. Michelline de Souza, do setor de Comunicação, que viabilizou a liberação de recursos para a confecção do tapete do quiz; a Coordenação do Curso de Relações Internacionais, representada pela professora M. ${ }^{a}$ Carla Marinho Borba, pelo apoio institucional para o desenvolvimento dos trabalhos.

Agradecimentos também às equipes pedagógica e diretiva, aos professores e aos estudantes do Colégio Dehon, do Centro de Educação Profissional Diomício Freitas, da Escola de Educação Básica Henrique Fontes, do Serviço Nacional de Aprendizagem Industrial, da Escola de Educação Básica Dr. Renato Ramos da Silva, da Escola de Ensino Médio Almirante Lamego, da Escola de Ensino Médio Dite Freitas, da Escola Técnica do Comércio de Tubarão e da Escola de Educação Básica e Profissional Professora Adélia Cabral Varejão (Fundação Bradesco) pela abertura, apoio e receptividade.

Para finalizar, faz-se um agradecimento sui generis a Pró-Reitoria de Ensino, Pesquisa e Extensão da Unisul (PROEPEx), em particular à professora Dra. Milene Pacheco 
Kindermann, coautora deste artigo, coordenadora do projeto e coordenadora de extensão universitária.

\section{REFERÊNCIAS}

BRASIL é segundo país com pior nível de aprendizado, aponta estudo da OCDE. 2016. Disponível em: <http://educacao.uol.com.br/noticias/agenciaestado/2016/02/10/brasil-e-segundo-pais-com-pior-nivel-de-aprendizado-apontaestudo-da-ocde.htm>. Acesso em: 21 ago. 2016.

BRASIL. Decreto $\mathbf{n}^{\mathbf{0}} \mathbf{1 9 . 8 4 1}$, de 22 de outubro de 1945. Promulga a Carta das Nações Unidas, da qual faz parte integrante o anexo Estatuto da Corte Internacional de Justiça, assinada em São Francisco, a 26 de junho de 1945, por ocasião da Conferência de Organização Internacional das Nações Unidas. 1945. Disponível em: <http://www.planalto.gov.br/ccivil_03/decreto/1930-1949/d19841.htm> Acesso em: 23 ago. 2016.

ESTADO DE SANTA CATARINA. Secretaria de Desenvolvimento Regional de Tubarão. Plano de Desenvolvimento da Secretaria de Desenvolvimento Regional de Tubarão - $\quad$ PDR. Tubarão, 2012. Disponível em: <http://www2.spg.sc.gov.br/fmanager/spg/pdrs\%202013/pdr_tubarao.pdf>. Acesso em: 21 ago. 2016

ESTADO DE SANTA CATARINA. Lucio Baggio. Agência Assembleia Legislativa do Estado de Santa Catarina. Estrutura física das escolas estaduais é debatida em audiência pública. 2016. Disponível em: $<$ http://agenciaal.alesc.sc.gov.br/index.php/noticia_single/estrutura-fisica-das-escolasestaduais-e-debatida-em-audiencia-publica>. Acesso em: 21 ago. 2016.

SILVA, A. F.; SOUZA, A. L. L. Condições do trabalho escolar: desafios para os sistemas municipais de ensino. Cad. Pesqui., São Paulo, v. 43, n. 150, p. 772-787, dez. 2013. Disponível em: <http://www.scielo.br/scielo.php?script=sci_arttext\&pid=S010015742013000300003\&lng=pt\&nrm=iso>. Acesso em: 21 ago. 2016.

UNIVERSIDADE DO SUL DE SANTA CATARINA. Curso de Relações Internacionais. Projeto Pedagógico do Curso de Relações Internacionais. Tubarão, 2013. Documento interno.

UNIVERSIDADE FEDERAL DOS VALES DO JEQUITINHONHA E MUCURI. PIBID Programa Institucional de Bolsas de Iniciação à Docência. Disponível em: <http://www.ufvjm.edu.br/prograd/pibid.html>. Acesso em: 28 ago. 2016. 